The International Journal of Indian Psychology

ISSN 2348-5396 (e) | ISSN: 2349-3429 (p)

Volume 5, Issue 1, DIP: 18.01.106/20170501

DOI: $10.25215 / 0501.106$

http://www.ijip.in | October-December, 2017

Original Research Paper

\title{
Influence of Parenting Styles on Shyness among Adolescents
}

\author{
Ahmad Rezvan $^{1 *}$, Lancy D’Souza ${ }^{2}$, Fatemeh Shapouri ${ }^{3}$
}

\section{ABSTRACT}

The current study intended to investigate the influence of parenting styles on shyness among adolescents. A sample of 200 subjects whose age ranged between 11 to 14 years was considered as early adolescents in the present study. Thus, a total sample of 200 subjects (100 boys and 100 girls) from in and around Mysore city were randomly selected as the participants of the study. They were provided with Parental authority questionnaire (PAQ; Buri, 1991) to measure perceived parenting styles -permissive, authoritative and authoritarian, and Shyness Assessment Test (SAT; D’Souza,2006), which measured shyness in three domains-cognitive/affective, physiological and action oriented. Two-way ANOVA was employed to find out the influence of parenting styles and gender, and school type on shyness. Results revealed that parenting styles had significant influence over physiological domain and total shyness scores, where adolescents with permissive parenting styles were shyer than adolescents with authoritative and authoritarian parenting styles. Female adolescents were shyer than male adolescents in all the domains of shyness including total shyness. Adolescents studying in government schools were shyer than adolescents studying in aided and unaided schools in action oriented domain of shyness and total shyness.

Keywords: Adolescence, Parenting Styles, Shyness

Parenting style is a psychological vocabulary representing standard strategies that parents use in their child raising. The parenting quality is more prominent compared time spent with the child. For instance, a parent may be spending the entire afternoon along with his or her child, yet the parent himself may be getting engaged in a different activity and not bestowing sufficient interest of care towards the child. Parenting styles represent how parents respond and react towards their children. Parenting practices include specific behaviours, while parenting styles represent broader systems of parenting practices. There are several theories and opinions regarding the best and ideal ways to rear children, as well as varying amounts of time and effort that parents are willing to spent. Children pass through different stages in their life; therefore and parents establish their own parenting styles dram

\footnotetext{
${ }^{1}$ Research Scholar, Dept. Of Psychology, University of Mysore, India

${ }^{2}$ Associate Professor, Department of Psychology, Maharaja's College, University of Mysore, India

${ }^{3}$ English Teacher in Chochn Education, India

*Responding Author

(C) 2017 Rezvan A, D'Souza L \& Shapouri F; licensee IJIP. This is an Open Access Research distributed under the terms of the Creative Commons Attribution License (www.creativecommons.org/licenses/by/2.0), which permits unrestricted use, distribution, and reproduction in any Medium, provided the original work is properly cited.
} 


\section{Influence of Parenting Styles on Shyness among Adolescents}

from a combination of factors that was evolved over time when children learn to develop their own personalities. During infancy stage, parents try to adjust to the new lifestyle by adapting and bonding with their new infant. For example, the relationship between the parent and the child is attachment. When children search the stage of adolescence, parents encounter new challenges, such as adolescents seeking and desiring to have freedom. A child's temperament and parents' cultural background have some influence on the type of parenting style a child is going to receive. The exeunt to which a child's education forms part of parenting is a matter of debate. Early research in parenting and child development has shown that parents who provide proper nurture to their children as well as independence and firm control, will develop levels of competence and become socially skilled and proficient. Additional developmental skills will result from positive parenting styles including: maintaining a close relationship with others, being self-reliant, and in depend. During mid-1980s, researchers began to explore how some specific parenting styles influence a child's later development.

One of the problems closely associated with emotional and interpersonal relationships, which is the subject receiving growing attention by educational experts, psychologists and family counselors in recent years, is the issue of shyness. In the past, shyness was treated as a borderline positive trait commonly confused with traits such as modesty. Today, shyness and unpleasant sense of failure in interpersonal relationships are considered as problems identical to social disabilities, which can seriously hamper the socialization and social adaptation of individuals in the society (Afrouz., 1997, p. 143). Shyness in other words refers to the discomfort and behavioral inhibition in social situations, a fear of negative evaluation accompanied by emotional distress or inhibition that interferes significantly with participation in desired activities and in the pursuit of personal and professional goals (Henderson \& Zimbardo, 1998). It is apparent that higher shyness will have enhanced negative influence on individuals' psychology and behavior. In case of high school students who are in the late adolescent stage, their physical and psychotically nature are changing rapidly. The gradual maturity of sexual physiology, the initiation of sex psychology, and the rapid development of self-consciousness all push them toward more shyness when they face the situation of meeting opposite sex, or under circumstances concerning this self-evaluation especially negative evaluation. Modest shyness would not cause serious consequences, if the shyness level becomes too high, it may be harmful and troublesome to individuals 'adjustment and development, such as academic, emotion, dating, marriage, career and such others and some time it may, even lead to social anxiety and mental disorders, which will be detrimental individuals’ health and development (Jakobsen, Horwood, \& Fergusson, 2012).

Some studies have been done, which revealed the influence of parenting styles on shyness among their wards. Taghva, Rezaei, Irandost and Khaledian.(2013), found that the permissive parenting methods and arbitrary parenting have shown positive effects on students' shyness to a significant extent. Also remarkable negative relationship was observed between authoritative parenting methods and students' shyness. They concluded that authoritative parenting methods lead to less shyness among students. YingMin, , XiaoRan, LiNa, YunPeng 
and Xue, (2015) in their study found that parents' excessive protection and interference of parenting style and alienation dimension of parent-child attachment have significant positive prediction on shyness level of high school students; paternal emotional warmth has significant negative prediction on students' shyness level; and the parent-child attachment showed partial mediating effect on the relationship between the parenting style and shyness level of late adolescent students. They further concluded that Parenting style not only can directly affect late adolescence students' shyness, but also indirectly affect their shyness through parent-child attachment. Yazdkhasti and Alibloandi (2016), observed significant positive relationship between the permissive parenting style and shyness in children. Shyness tends to be more in strict authoritative parenting style. Also significant negative correlation was noticed between authoritarian parenting style and shyness, implying that authoritative parenting style is more likely to mitigate shyness in preschoolers. Piguo, Yunpeng and Fengqiang (2015) found negative correlation between the child shyness and the authoritative parenting style. The authoritarian parenting style has a negative predictive effect on boy's shyness.

The present study makes an attempt to evaluate the effect of different types of parenting styles on the shyness among adolescents, since the previous studies have reported contradictory findings. It is presumed that Parental styles will have marked influence on the shyness among adolescents. Also, the study aims to find out the influence of gender and school type on shyness among adolescents.

\section{MATERIALS AND METHODS}

\section{Participants:}

The participants of this study included 200 adolescent's (100 boys and 100 girls) selected randomly from different schools and colleges situated in both Urban and Rural areas in and around Mysore city. The age of the participants ranged from 11 to 19 years.

\section{Tools:}

\section{Parental authority questionnaire (PAQ; Buri, 1991)}

The PAQ had two types of forms, one relating to mothers' parental authority, and the other to fathers' parental authority. Each form consisted 30 items. Response to each item is made on a 5-point Likert scale ranging from strongly disagree (1) to strongly agree (5). The PAQ yields separate scores for each participant; mother's permissiveness, mother's authoritarianism, mother's authoritativeness, father's permissiveness, father's authoritarianism, and father's authoritativeness. The scores range from 10-50, in which higher scores indicate that parent is sharing majority of the characteristics of the particular parenting style.

\section{Shyness Assessment Test (SAT):}

Shyness Assessment Test (SAT): Shyness Assessment Test developed by D’Souza (2006), It consists of 54 items and requires the subject to indicate his/her response by marking Yes, or No. If the answer is 'yes', further, the participant has to indicate one of the three levels-low, medium or high. The items in the test pertain to three domains of shynessCognitive/Affective (32 items), Physiological (11 items) and Action oriented (11 items). The 
reliability index ascertained by split half (odd-even) method and Cronbach's alpha coefficient for the scale as a whole were found to be 0.735 and 0.812 respectively.

\section{Procedure:}

The research was conducted using descriptive research design as it described the phenomena under study in its natural settings. The study was carried out in Mysore City situated in Karnataka state. The study targeted 200adolescents with age among of 11 to 19 years from schools and college. Random sampling was done to select the 200 students. A prior appointment was made with school authorities in Mysore to apprise them of the objectives of the study and to obtain their permission for data collection. Afterwards, a tentative schedule for data collection was developed in discussion with the authorities. Later, taking permission from the concerned authority, subjects were assessed on parental authority questionnaire (PAQ) and Shyness Assessment Test (SAT) Further, data were analyzed using descriptive statistics and two way ANOVA.

Table 1: Mean shyness scores of male and female adolescents on various domains shyness with different parenting styles and results of 2-way ANOVA

\begin{tabular}{|c|c|c|c|c|c|c|c|c|c|}
\hline \multirow{3}{*}{$\begin{array}{l}\text { Parenting } \\
\text { style }\end{array}$} & & \multicolumn{8}{|c|}{ Domains of shyness } \\
\hline & \multirow[b]{2}{*}{ Gender } & \multicolumn{2}{|c|}{ Cognitive/affective } & \multicolumn{2}{|c|}{ Physiological } & \multicolumn{2}{|c|}{ Action oriented } & \multicolumn{2}{|c|}{ Total shyness } \\
\hline & & Mean & S.D & Mean & S.D & Mean & S.D & Mean & S.D \\
\hline \multirow{3}{*}{ Permissive } & Male & 31.64 & 10.08 & 5.70 & 3.28 & 6.57 & 3.50 & 43.91 & 10.46 \\
\hline & Female & 37.56 & 8.53 & 6.41 & 2.93 & 8.23 & 4.01 & 52.20 & 6.23 \\
\hline & Total & 34.81 & 9.70 & 6.08 & 3.11 & 7.46 & 3.86 & 48.34 & 9.39 \\
\hline \multirow{3}{*}{ Authoritative } & Male & 27.48 & 10.23 & 3.88 & 1.92 & 5.76 & 3.61 & 37.12 & 12.21 \\
\hline & Female & 36.00 & 7.00 & 5.76 & 2.25 & 8.71 & 2.93 & 50.47 & 6.71 \\
\hline & Total & 30.93 & 9.91 & 4.64 & 2.24 & 6.95 & 3.62 & 42.52 & 12.20 \\
\hline \multirow{3}{*}{ Authoritarian } & Male & 28.64 & 9.69 & 4.45 & 3.39 & 5.45 & 3.60 & 38.55 & 13.65 \\
\hline & Female & 33.91 & 9.65 & 5.86 & 2.78 & 7.05 & 4.02 & 46.82 & 12.76 \\
\hline & Total & 31.27 & 9.92 & 5.16 & 3.15 & 6.25 & 3.85 & 42.68 & 13.71 \\
\hline \multirow{3}{*}{ Total } & Male & 29.94 & 10.10 & 4.97 & 3.10 & 6.12 & 3.55 & 41.03 & 11.95 \\
\hline & Female & 36.49 & 8.60 & 6.18 & 2.79 & 8.05 & 3.86 & 50.72 & 8.37 \\
\hline & Total & 33.22 & 9.92 & 5.58 & 3.00 & 7.09 & 3.82 & 45.88 & 11.38 \\
\hline F (Par style) & \multicolumn{3}{|c|}{$\mathrm{F}=2.71 ; \mathrm{p}=.069$} & \multicolumn{2}{|c|}{$\mathrm{F}=3.32 ; \mathrm{p}=.038$} & \multicolumn{2}{|c|}{$\mathrm{F}=1.55 ; \mathrm{p}=.215$} & \multicolumn{2}{|c|}{$F=5.72 ; p=.004$} \\
\hline F (Gender) & \multicolumn{3}{|c|}{$F=19.86 ; p=.001$} & \multicolumn{2}{|c|}{$\mathrm{F}=8.39 ; \mathrm{p}=.004$} & \multicolumn{2}{|c|}{$\mathrm{F}=12.44 ; \mathrm{p}=.001$} & \multicolumn{2}{|c|}{$\begin{array}{c}F=39.28 \\
p=.001\end{array}$} \\
\hline $\begin{array}{c}\mathrm{F} \\
\text { (Interaction) }\end{array}$ & \multicolumn{3}{|c|}{$F=0.38 ; p=.686$} & \multicolumn{2}{|c|}{$F=0.68 ; p=.508$} & \multicolumn{2}{|c|}{$\mathrm{F}=0.50 ; \mathrm{p}=.608$} & \multicolumn{2}{|c|}{$\mathrm{F}=1.10 ; \mathrm{p}=.363$} \\
\hline
\end{tabular}


Influence of Parenting Styles on Shyness among Adolescents

Table 2: Mean shyness scores of adolescents studying in various types of schools on various domains shyness with different parenting styles and results of 2-way ANOVA

\begin{tabular}{|c|c|c|c|c|c|c|c|c|c|}
\hline \multirow{3}{*}{$\begin{array}{l}\text { Parenting } \\
\text { style }\end{array}$} & \multirow[b]{3}{*}{$\begin{array}{c}\text { School } \\
\text { type }\end{array}$} & \multicolumn{8}{|c|}{ Domains of shyness } \\
\hline & & \multicolumn{2}{|c|}{ Cognitive/affective } & \multicolumn{2}{|c|}{ Physiological } & \multicolumn{2}{|c|}{ Action oriented } & \multicolumn{2}{|c|}{ Total shyness } \\
\hline & & Mean & S.D & Mean & S.D & Mean & S.D & Mean & S.D \\
\hline \multirow{4}{*}{ Permissive } & Govt. & 35.77 & 8.30 & 5.86 & 2.83 & 7.89 & 3.95 & 49.51 & 7.97 \\
\hline & Aided & 32.76 & 10.69 & 5.91 & 3.36 & 6.96 & 3.74 & 45.62 & 10.92 \\
\hline & Unaided & 36.53 & 9.45 & 6.53 & 3.08 & 7.68 & 3.97 & 50.74 & 7.75 \\
\hline & Total & 34.81 & 9.70 & 6.08 & 3.11 & 7.46 & 3.86 & 48.34 & 9.39 \\
\hline \multirow{4}{*}{ Authoritative } & Govt. & 35.14 & 12.16 & 4.71 & 2.36 & 9.14 & 5.27 & 49.00 & 12.23 \\
\hline & Aided & 29.32 & 8.69 & 4.73 & 2.43 & 5.82 & 3.28 & 39.86 & 12.31 \\
\hline & Unaided & 31.38 & 10.69 & 4.46 & 1.98 & 7.69 & 2.53 & 43.54 & 11.41 \\
\hline & Total & 30.93 & 9.91 & 4.64 & 2.24 & 6.95 & 3.62 & 42.52 & 12.20 \\
\hline \multirow{4}{*}{ Authoritarian } & Govt. & 33.87 & 8.73 & 6.53 & 3.23 & 8.40 & 3.92 & 48.80 & 10.80 \\
\hline & Aided & 29.67 & 11.47 & 3.58 & 2.54 & 5.08 & 3.53 & 38.33 & 14.98 \\
\hline & Unaided & 30.50 & 10.08 & 4.88 & 3.07 & 5.00 & 3.39 & 40.38 & 14.38 \\
\hline & Total & 31.44 & 9.97 & 5.09 & 3.15 & 6.21 & 3.89 & 42.74 & 13.87 \\
\hline \multirow{4}{*}{ Total } & Govt. & 35.19 & 8.80 & 5.89 & 2.89 & 8.18 & 4.06 & 49.26 & 9.16 \\
\hline & Aided & 31.33 & 10.30 & 5.23 & 3.10 & 6.35 & 3.61 & 42.91 & 12.24 \\
\hline & Unaided & 33.94 & 10.12 & 5.68 & 2.99 & 7.00 & 3.71 & 46.62 & 11.34 \\
\hline & Total & 33.26 & 9.92 & 5.56 & 3.01 & 7.08 & 3.83 & 45.90 & 11.40 \\
\hline F (Par style) & \multicolumn{3}{|c|}{$F=2.79 ; p=.064$} & \multicolumn{2}{|c|}{$\mathrm{F}=4.33 ; \mathrm{p}=.014$} & \multicolumn{2}{|c|}{$\mathrm{F}=2.16 ; \mathrm{p}=.118$} & \multicolumn{2}{|c|}{$\begin{array}{c}F=2.86 \\
p=.003\end{array}$} \\
\hline F (Sch type) & \multicolumn{3}{|c|}{$F=2.33 ; p=.100$} & \multicolumn{2}{|c|}{$F=1.30 ; p=.276$} & \multicolumn{2}{|c|}{$\mathrm{F}=5.29 ; \mathrm{p}=.006$} & \multicolumn{2}{|c|}{$\begin{array}{l}\mathrm{F}=6.11 ; \\
\mathrm{p}=.003\end{array}$} \\
\hline $\begin{array}{c}\mathrm{F} \\
\text { (Interaction) }\end{array}$ & \multicolumn{3}{|c|}{$\mathrm{F}=0.36 ; \mathrm{p}=.837$} & \multicolumn{2}{|c|}{$F=1.65 ; p=.163$} & \multicolumn{2}{|c|}{$\mathrm{F}=1.40 ; \mathrm{p}=.236$} & \multicolumn{2}{|c|}{$\begin{array}{c}F=1.23 \\
p=.298\end{array}$} \\
\hline
\end{tabular}

Parenting style, gender and shyness: Parenting styles had significant influence over one domain of shyness and total shyness scores. In the case of physiological domain of shyness $(\mathrm{F}=3.2 ; \mathrm{p}=.038)$, we find that adolescents with permissive parenting styles had significantly higher shyness scores (mean 6.08) than adolescents with authoritative and authoritarian parenting styles (mean shyness scores 4.64 and 5.86 respectively), which were further confirmed by Scheffe's post hoc test. In total shyness scores, again we find a significant difference $(\mathrm{F}=5.72 ; \mathrm{p}=.004)$, where adolescents with permissive parenting styles had significantly higher total shyness scores (mean 48.34) than adolescents with authoritative and authoritarian parenting styles (mean shyness scores 42.52 and 46.82). Further, Scheffe's post hoc test indicated no mean difference in the shyness cores of adolescents with authoritative and authoritarian parenting styles and only adolescents with permissive parenting style had higher shyness scores.

Female adolescents were found to be shyer than male adolescents in all the domains of shyness-cognitive/affective ( $\mathrm{F}=19.86 ; \mathrm{p}=.001)$, physiological $(\mathrm{F}=8.39 ; \mathrm{p}=.004)$, action oriented $(\mathrm{F}=12.44 ; \mathrm{p}=.0010$ and in total shyness scores $(\mathrm{F}=39.28 ; \mathrm{p}=.001)$. However, all the 


\section{Influence of Parenting Styles on Shyness among Adolescents}

interaction effects obtained between parenting styles and gender were found to be nonsignificant.

\section{Parenting style, school type and shyness}

School type had significant influence over only one domain of shyness-action oriented and in total shyness scores. The F values obtained for action oriented domain and total shyness scores are 5.29 and 6.11 (with $\mathrm{P}$ values of .006 and .003 respectively). From the table it is clear that adolescents studying in government schools reported higher shyness than adolescents studying in aided and unaided schools/institutes both in action oriented and total shyness scores. However, all the interaction effects obtained between parenting styles and school were found to be non-significant.

\section{DISCUSSION}

\section{Main findings of the study:}

- $\quad$ Parenting styles had significant influence over physiological domain and total shyness scores, where adolescents with permissive parenting styles were shyer than adolescent's with authoritative and authoritarian parenting styles

- $\quad$ Female adolescents were shyer than male adolescents in all the domains of shyness including total shyness.

- $\quad$ Adolescents studying in government schools were shyer than adolescents studying in aided and unaided schools in action oriented domain of shyness and total shyness.

The current study examined the influence of parenting styles on shyness among adolescents. Results have shown that there is a close relationship between parenting style and adolescent's shyness.

Shyness quality hinders the growth of positive thoughts and dampens the self-confidence of one self. Shy individuals having shyness the capacity to lack understand about their own strengths and weakness thereby find difficult in adjusting themselves to various situations arising in their life. Several studies have tried to understand the factors which influence shyness in children and adolescents. These studies aimed at exploring the relation between shyness and parenting styles among adolescents. The present study looked into the influence of parenting styles on shyness among adolescents. Parenting style has close relation with adolescents shyness. The study results indicate that parenting styles had some definite influence over one domain of shyness as also on total shyness scores. Firstly, in physiological domain of shyness the results have shown that the adolescents with permissive parenting styles had significantly higher shyness scores than adolescents with authoritative and authoritarian parenting styles. This was also confirmed by Scheffe's post hoc test. This result is in consistent with other studies. It was found that rejecting rearing behavior and lack of emotional warmth in childhood, seemed to constitute as the risk factor for development of high harm avoidant behavior (anticipatory worry, fear of uncertainty, shyness) and low selfdirected behavior (blaming others, helplessness, lack of self-acceptance and low self-esteem) (Schletteet al., 1998). The reason for this being that parents' tow much interference and 
protection limit the children's independent acting ability and affect their normal communication with others. When the children have to face also some situations and problems, more withdrawal behaviors may come up which can lead to a vicious circle of shyness. The denial by parental would make their children experience more frustrations and their self-esteem gets impaired, as a consequence they fear of expressing themselves and develop a situation on the level of self-restriction, finally leading to the emergence of shyness (An \& Sheng, 2013).

We also find that in total shyness scores, a significant difference could be found where adolescents with permissive parenting styles significantly higher total shyness scores than adolescents with authoritative and authoritarian parenting styles. Further, Scheffe's post hoc test did not indicated mean difference in the shyness scores of adolescents with authoritative and authoritarian parenting styles and only adolescents with permissive parenting style had higher shyness scores.

In summary, during adolescence stage, the influence of parenting style on their children's shyness continue to persist. This influence is directly reflected in the effect of parenting style on shyness. Parents should adopt positive parenting style, such as emotional warmth, and avoid the negative parenting styles, such as two much interference, rejection and denial. This will lead to the formation of a good parent-child relationship, which will contribute to reduce adolescence's shyness. When parents trust their children, and communication continue have more with children, it will pave the way far establishing a better parent-child relationship, children would gain more confidence and a sense of security, their psychological inferiority and timid behavior would also get reduced leading to free behavior at the time of facing others (Prevatt, 2003; Susanna et al., 2014).

\section{Acknowledgments}

The author appreciates all those who participated in the study and helped to facilitate the research process.

Conflict of Interests: The author declared no conflict of interests.

\section{REFERENCES}

Afroz, G. (1997). The shyness psychology, II edition. Tehran: Daftare Nashre Farhangi Publications.

An, X., \& Sheng, Y. (2013). Relationship between parenting, shyness and fear of negative evaluation. China Journal of Health Psychology, 21(3), 434-437.

Buri, J. R. (1991). Parental authority questionnaire. Journal of personality assessment, 57(1), 110-119.

D’Souza, L. (2006). Shyness assessment test. Mysore: University of Mysore.

Henderson, L., \& Zimbardo, P. (1998).Encyclopedia of Mental Health. San Diego, CA: Academic Press. Retrieved from: http://www.shyness.com/encyclopedia.html. 
Jakobsen, I. S., Horwood, L. J., \& Fergusson, D. M. (2012). Childhood anxiety/withdrawal, adolescent parent-child attachment and later risk of depression and anxiety disorder. Journal of Child and Family Studies, 21(2), 303-310

Piguo,H., Yunpeng, Wu \& Fengqiang, G (2015)The Relationship Between Parent Shyness and Child Shyness: Examining the Moderating Effect of Child Gender and Parenting Style. Psychology Research,5(1),23-31.

Prevatt, F. F. (2003). The contribution of parenting practices in a risk and resiliency model of children's adjustment. British Journal of Developmental Psychology, 21(4), 469-480.

Schlette, P., Brändström, S., Eisemann, M., Sigvardsson, S., Nylander, P. O., Adolfsson, R., \& Perris, C. (1998).Perceived parental rearing behaviours and temperament and character in healthy adults. Personality and Individual Differences, 24(5), 661-668..

Susanna, P., Roberto, B., Barry, H. S., Sheri, M., \& Leslie, A. (2014). Early child-parent attachment and peer relations: A meta-analysis of recent research. Journal of Family Psychology, 28(1), 118-123.

Taghva, R., Rezaei, F., Irandost, R \& Khaledian, M. (2013).Studying the Relationship between Parenting Methods and Students' Shyness in the High Schools of Eghlid City .Journal of Novel Applied Sciences. 2 (12): 757-762.

Yazdkhzdkhasti, A\& Alibloandi,A(2016),The relationship between parenting style and shyness in preschoolers. International Journal of Biology, Pharamcy and Seiences,5(1),668-677.

YingMin, C., XiaoRan, L., LiNa, Y., YunPeng, W., \&Xue, H. (2015). Parenting Style and Shyness of Late Adolescence Students in China: The Mediating Effect of ParentChild Attachment. Psychology, 5(7), 404-412.

How to cite this article: Rezvan A, D'Souza L \& Shapouri F (2017). Influence of Parenting Styles on Shyness among Adolescents. International Journal of Indian Psychology, Vol. 5, (1), DIP: 18.01.106/20170501, DOI: 10.25215/0501.106 